\title{
PEMILIHAN NODE TETANGGA YANG HANDAL DENGAN MEMPERHITUNGKAN SIGNAL STRENGTH DAN LINK QUALITY PADA ZONE ROUTING PROTOCOL DI LING- KUNGAN MANET
}

\author{
Ida Bagus Ary Indra Iswara ${ }^{1}$, Waskitho Wibisono ${ }^{2}$ \\ ${ }^{1}$ Jurusan Teknik Informatika, Fakultas Teknologi Informasi, Institut Teknologi Sepuluh Nopember \\ Kampus ITS Keputih Sukolilo, Surabaya, Jawa Timur \\ ${ }^{2}$ Jurusan Teknik Informatika, Fakultas Teknologi Informasi, Institut Teknologi Sepuluh Nopember \\ Kampus ITS Keputih Sukolilo, Surabaya, Jawa Timur \\ Email: aryindraiswara@gmail.com
}

\begin{abstract}
Zone Routing Protocol (ZRP) is a hybrid routing protocol on MANET, because the routing protocol is base on two protocols, namely IntrAzone Routing Protocol (IARP) and IntErzone Routing Protocol (IERP). Through IARP, each node identifies distance to all nodes in its routing zone. Although the network is very large, the update process is only distribute locally in its routing zone only and not the whole network. While IERP protocol is responsible to find a route to a node that is located outside the zone. The selection of neighboring nodes completely done by Neighbor Discovery Protocol (NDP), which is performe by the node selection NDP is sending beacons broadcast message. NDP only use TTL to decide whether the neighboring nodes in broken or maintained.

In this research, the method of signal strength based link-sensing stability adaptation into the work process of the NDP. This method works based on the signal strength of a node. Signal strength of a node are reliable if the node does not exceed the predetermined threshold value. Reliable nodes that will be stored in the neighbor table and will be a reference to the IARP routing process. Nodes are not reliable will be disconnected and will not send beacons at the message again.

The selection of reliable neighbor nodes by calculating signal strength and link quality is able to improve the performance of ZRP routing protocols. Protocols tested in scenarios designed by the wide variation area. The test results showed an increase of 4:13 kbps increase in throughput, a decrease of 9.98 ms e2e delay and routing overhead decreased by $3.83 \%$.
\end{abstract}

Keywords: MANET, ZRP, Link Quality, Signal Strength, JiST/SWANS

\begin{abstract}
ABSTRAK
Zone Routing Protocol (ZRP) merupakan protokol routing hybrid pada MANET, karena protokol routing ini didasarkan pada dua protokol yaitu IntrAzone Routing Protokol (IARP) dan IntErzone Routing Protokol (IERP). Melalui IARP, setiap node mengidentifikasi jarak ke semua node di zona routing-nya. Meskipun jaringannya sangat besar, proses update hanya disebarkan secara lokal pada zona routing-nya saja dan tidak pada keseluruhan jaringan. Sedangkan protokol IERP bertanggung jawab untuk menemukan rute ke node yang terletak di luar zona. Pemilihan node tetangga sepenuhnya dilakukan oleh Neighbor Discovery Protocol (NDP), pemilihan node yang dilakukan oleh NDP adalah mem-brodcast beacons message. NDP hanya memanfaatkan TTL untuk memutuskan apakah node tetangga tersebut di putus atau dipertahankan.

Pada penelitian ini dilakukan adaptasi metode signal strength based link-stability sensing, ke dalam proses kerja NDP. Metode ini bekerja berdasarkan dari kekuatan signal suatu node. Kekuatan signal (signal strength) suatu node dikatakan reliable apabila node tersebut tidak melebihi nilai threshold yang sudah ditentukan. Node yang reliable akan disimpan pada tabel neighbor dan selanjutnya akan dijadikan acuan untuk melakukan proses routing pada IARP. Node yang tidak reliable akan diputus dan tidak akan di kirimi beacons message lagi.

Pemilihan node tetangga yang handal dengan memperhitungkan signal strength dan link quality mampu memperbaiki kinerja dari protokol routing ZRP. Protokol diujikan ke dalam skenario yang dirancang berdasarkan variasi luas area. Hasil pengujian menunjukan peningkatan peningkatan throughput sebesar 4.13 kbps, penurunan e2e delay sebesar $9.98 \mathrm{~ms}$ dan penurunan routing overhead sebesar $3.83 \%$.
\end{abstract}

Kata kunci: MANET, ZRP, Link Quality, Signal Strength,JiST/SWANS 


\section{PENDAHULUAN}

Mobile Ad-hoc Networks (MANET) terdiri dari host mobile yang dapat berkomunikasi satu sama lain menggunakan link nirkabel. Dalam lingkungan ini rute antara dua host dapat terdiri dari banyak hop melalui satu atau lebih node di MANET (Ravilla dan Putta C., 2012). Node pada MANET memiliki beberapa kekurangan, seperti bandwidth terbatas, perangkat power yang rendah, perubahan topologi jaringan yang dinamis. (Jain, dkk., 2012). Komunikasi link di MANET juga rentan dan sensitif terhadap karakteristik saluran yang bervariasi. Pembentukan rute dan rekonstruksi rute merupakan dua fase penting dalam MANET yang harus ditangani dengan hati-hati (C. Biradar dan S. Manvi, 2012). MANET akan mendapatkan kinerja yang maksimal apabila setiap node dapat memanfaatkan sumber dayanya sendiri dan sebagai gantinya juga dapat memanfaatkan sumber daya node yang lain (Wrona dan Mahonen, 2004)

Routing pada MANET secara garis besar dibagi kedalam tiga kelompok yaitu proaktif routing, reaktif routing dan hybrid routing (Asha, dkk., 2012). Protokol routing proaktif contohnya adalah DSDV, OLSR,, protokol routing yang reaktif antara lain AODV, ODMRP, dan AOMDV, sedangkan protokol routing hybrid merupakan protokol routing yang menggabungkan kedua kelebihan dari proaktif dan reaktif routing, salah satu protokol routing hybrid adalah Zone Routing Protocol (ZRP).

Zone Routing Protocol (ZRP) merupakan protokol routing hybrid, karena protokol routing ini didasarkan pada dua protokol yaitu IntrAzone Routing Protokol (IARP) dan IntErzone Routing Protokol (IERP) (J. Haas, dkk., 2003). Melalui IARP, setiap node mengidentifikasi jarak ke semua node di zona routing-nya. Meskipun jaringannya sangat besar, proses update hanya disebarkan secara local pada zona routing-nya saja dan tidak pada keseluruhan jaringan. Sedangkan protokol IERP bertanggung jawab untuk menemukan rute ke node yang terletak di luar zona (Beijar, 2002). Selain kedua protokol tersebut ZRP juga didukung Bordercast Resolution Protocol (BRP) yang bertugas sebagai perantara komunikasi antara IARP dengan IERP dan Neighbor Routing Protocol (NDP) yang bertugas untuk mencari dan mencatat node tetangga yang ada pada IARP (Beijar, 2002)

Neighbor Routing Protocol (NDP) memiliki peranan yang sangat penting pada proses routing di ZRP. NDP merupakan sumber informasi dari keberadaan node-node yang berada pada zone IARP. NDP melakukan pendataan node tetangga dengan melakukan broadcast beacons message yang disebar ketetangga yang terkoneksi, beacon message yang dikirim berisikan MAC Address, IP Address, Destination, Source, apabila broadcast beacons message mendapakan jawaban maka jawaban tersebut dijadikan indikator bahwa node tersebut merupakan tetangga dan akan disimpan pada tabel neighbor yang dimiliki NDP. Node dianggap tidak valid apabila node tersebut tidak mengirimkan balasan selama batasan waktu yang dialokasikan, dan tabel tersebutlah yang akan menjadi acuan bagi IARP untuk melakukan proses routing (Beijar, 2002; Shafiq, Mahmud, Khan, Sayyed, \& Al-Raweshidy, 2012).

Mengingat MANET adalah jaringan yang bersifat mobile maka node-node yang berada pada suatu zone di ZRP sangat mungkin mengalami perubahan tempat. Perubahan tempat suatu node akan berdampak pada koneksi antar node yang sebelumnya sudah terbangun. Sistem discovery node yang ditawarkan oleh ZRP klasik adalah NDP, NDP seperti dijelaskan diatas hanya menampung MAC, dan IP Address dari node tetangga, hal ini akan menyebabkan sebuah masalah ketika nodenode yang berada dalam zone mengalami pergerakan. NDP hanya mampu mengetahui IP dan MAC saja dan tidak mengetahui apakah node tersebut masih bisa menerima beacons message atau tidak. Indikator yang digunakan NDP saat ini untuk menentukan apakah sebuah node merupakan tetangga yang valid atau tidak adalah menunggu balasan beacons message yang dikirimkan selama batas waktu yang ditentukan (Beijar, 2002). Berdasarkan hal yang disebutkan diatas maka peneliti mengusulkan penerapan metode baru untuk melakukan pemilihan node tetangga dengan signal strength based link-stability sensing. Pemilihan node dengan metode ini berdasarkan dari kekuatan signal suatu node. Kekuatan signal (signal strength) Suatu node dikatakan reliable apabila node tersebut tidak melebihi nilai threshold yang sudah ditentukan. Node yang reliable akan disimpan pada tabel neighbor dan selanjutnya akan dijadikan acuan untuk melakukan proses routing pada IARP. Node yang tidak reliable akan diputus dan tidak akan dikirimikan beacons message lagi. Dengan metode signal strength based link stability sensing diharapkan dapat meningkatkan kinerja dari protokol routing ZRP.

\section{METODE SIGNAL STRENGTH LINK-STABILITY SENSING}

Metode signal strength based linkstability sensing dibagi dalam tiga tahapan yaitu tahap perhitungan signal strength tahap penentuan threshold dan tahap perhitungan link quality. Tahap-tahap tersebut akan diterangkan lebih rinci pada sub-bab berikut. 


\subsection{Tahap Perhitungan Signal Strength}

Perhitungan signal strength yang digunakan pada penelitian ini adalah dengan menggunakan persamaan dari two ray ground reflection model. Two ray ground reflection model mempertimbangkan jalur langsung dan jalur refleksi tanah. Hal ini menunjukkan bahwa model ini memberikan prediksi yang lebih akurat pada jarak jauh dibandingkan dengan model ruang bebas.

Penelitian ini menggunakan Persamaan 1 untuk melakukan perhitungan signal strength. Persamaan 1 akan berdampak pada signal strength dari suatu node ketika nilai $d$ semakin besar maka $s s$ akan menjadi semakin kecil. Oleh karena itu dibuatlah threshold untuk membatasi suatu node apakah masih bisa berkomunikasi atau tidak.

$$
(s s)=\frac{1}{d^{4}}
$$

Dimana :

ss $=$ Signal Strength

$\mathrm{d}=$ Jarak antar node

Hasil yang didapatkan dari perhitungan dengan menggunakan Persamaan 1 digunakan sebagai acuan untuk digunakan pada perhitungan link-quality.

Perhitungan link-quality sangat berpengaruh dari hasil perhitungan signal strength dengan menggunakan Persamaan 1. Hasil dari perhitungan menggunakan Persamaan 1 dapat dilihat pada Gambar 1, pada Gambar tersebut diperlihatkan penurunan kwalitas signal seiring bertambahnya nilai jarak yang semakin jauh.

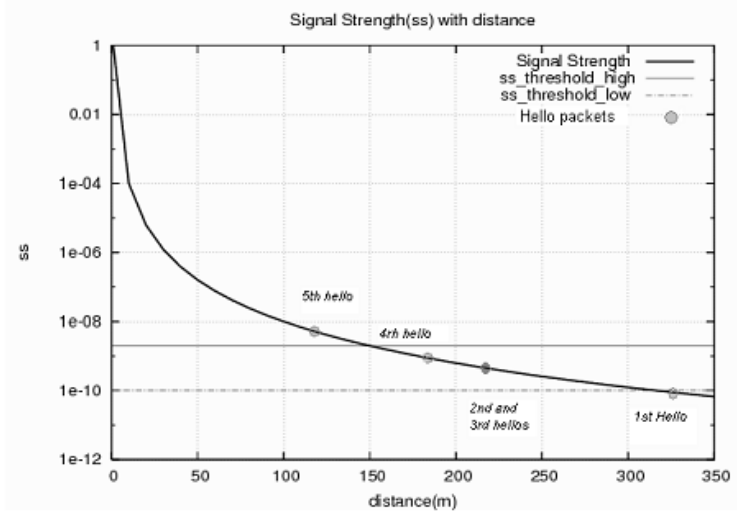

Gambar 11 Signal Strength vs Distance

\subsection{Tahap Penentuan Threshold}

Penentuan nilai Threshold ditentukan berdasarkan Gambar 1. Pada Gambar 1 terlihat nilai threshold_high dan nilai threshold_low ditunjukan oleh garis horizontal yang membentang pada Gambar 1. threshold_high digambarkan dengan garis horizontal lurus tanpa putus-putus, sedangkan untuk threshold_low digambarkan dengan garis horizontal lurus dengan putus-putus. Nilai threshold_high adalah diantara nilai ss 1e-08 dengan 1e-
09, sedangkan threshold_low berada diantara ss 1e09 dengan 1e-10.

Nilai epsilon yang didapatkan berdasarkan dari Gambar 1 berikutnya akan dirubah kedalam nilai logarithmic.

Berdasarkan nilai threshold yang digunakan pada paper yang dibuat oleh (Ali, dkk., 2009) yaitu untuk nilai threshold_high adalah -8.9 dan untuk nilai threshold_low adalah -9.3. Untuk nilai threshold_high didapatkan dari persamaan dibawah ini

threshold_high $=\log (1 \mathrm{e}-8.9)=\log \left(1 \times 10^{-8.9}\right)$

$$
=-8.9
$$

Sedangkan untuk threshold_low juga menggunakan persamaan yang sama untuk memperoleh nilai logarithmic dari nilai ss yang bernilai 1e-9.3, untuk perhitungan threshold_low dapat dilihat seperti dibawah ini

$\begin{aligned} \text { threshold_low } & =\log (1 \mathrm{e}-9.3)=\log \left(1 \times 10^{-9.3}\right) \\ & =-9.3\end{aligned}$

$$
=-9.3
$$

Nilai threshold inilah yang selanjutnya akan digunakan dalam perhitungan link-quality pada sub-bab berikut.

\subsection{Tahap Perhitungan Link Quality}

Tahapan perhitungan link-quality dilakukan berdasarkan informasi signal strength yang diterima dari node-node sekitarnya. Ada beberapa indikator yang digunakan pada perhitungan linkquality ini antara lain adalah adanya threshold_high, threshold_low, Hyst_ss_scaling dan juga delta. Tahapan perhitungan link-quality adalah sebagai berikut :

1. Ketika paket hello pertama diterima dengan signal strength di bawah ss_threshold_high, maka paket tersebut tidak dianggap sebagai reception jadi link-quality tidak diinisialisasi. Hanya paket dengan signal strength di atas ss_threshold_low yang akan diinisialisasi link-quality-nya

2. Paket Hello kedua berada di atas ss_threshold_low dengan demikian linkquality diinisialisasi, tetapi link_status masih tertunda oleh karena itu, link tidak dapat digunakan untuk mengirimkan pesan kepada siapapun. Ketika node menerima paket lain pada sekitar tingkat daya yang sama, tidak berdampak pada link-quality.

3. Jadi Setiap kali perbedaan dalam signal strength, yang terakumulasi, melintasi nilai tertentu dari $\Delta$, link-quality rewarded atau punished berdasarkan peningkatan atau penurunan masing-masing.

4. Penggunaan $\Delta$ memungkinkan untuk rewarded hanya node yang mendekati dan node yang tidak akan tinggal pada jarak yang sama antar hello berturut-turut. 
Pemberiaan rewarded dan Punished antar ambang untuk setiap perubahan $\Delta$, dilakukan untuk membuat link lebih kuat dan mengurangi waktu yang dibutuhkan dalam mengubah status link. Ketika sebuah paket dengan signal strength di atas ss_threshold_high diterima, link-quality rewarded dan selama link-quality melintasi ambang batas, link menjadi aktif (link_pending $=$ false $)$.

\section{DISAIN SISTEM}

Pada penelitian ini protokol LinkStability Zone Routing Protocol (LS-ZRP) dirancang dengan mengintegrasikan Signal Strength Based Link-Stability Sensing, untuk melakukan pemilihan node tetangga yang reliable berdasarkan signal strength dari node tetangga. Metode ini diterapkan pada sub-protokol pada Zone Routing Protocol (ZRP). Desain ini diharapkan mampu menjaga link-stability antar node untuk mendapatkan rute yang stabil untuk dilalui pada ZRP. Untuk menjaga link-stability antar node diterapkanlah metode Signal Strength Based LinkStability Sensing pada Neighbor Discovery Protocol (NDP) dengan memodifikasi HELLO Beacons yang dikirimkan ke semua node tetangga. HELLO Beacons yang dimodifikasi seperti pada Gambar 3.2 akan memberikan informasi tetangga mengenai ip, jarak, signal strength dll. Hal ini dijadikan acuan untuk memilih apakah node tetangga yang dikirimi HELLO Beacons merupakan node yang reliable atau tidak, jika node tersebut reliable maka akan disimpan pada tabel node yang reliable. Tabel node reliable yang dihasilkan oleh NDP selanjutnya akan menjadi acuan IntrAzone Routing Protocol (IARP) dalam proses penentuan rute routing menuju ke node tujuan
Pengembangan Protokol Routing LSZRP dilakukan dengan cara menurunkan sifat ZRP asli dan dimodifikasi dengan metode Signal Strength Based Link-Stability Sensing. Pada paket header ZRP ditambahkan signal strength status untuk menampung nilai dari signal strength sebuah node. Signal strength ini akan ditambahkan seperti terlihat pada Gambar 2.

Nilai yang didapat dari signal strength status pada paket header digunakan untuk melakukan pencarian node tetangga yang reliable pada penerapan Signal Strength Based LinkStability Sensing.

\subsection{Pengembangan Protocol NDP dengan Link- Stability Sensing}

Pada tahapan ini dipaparkan flowchart dari hasil pengembangan NDP dengan metode Signal Strength Based Link-Stability Sensing.

Flowchart sistem yang terlihat pada Gambar 3, merupakan modifikasi dari flowchart NDP. Modifikasi dilakukan dengan menambahkan perhitungan signal strength dan link-stability pada dua tahapan NDP yaitu pada tahap Inisialisasi beacons message dan pada proses pengecekan tabel neighbor.

Perhitungan signal strength (SS) dilakukan ketika paket yang diterima di extrak kemudian dari data paket yang diterima dilakukan perhitungan SS dari node yang mengirimkan paket. Selanjutnya adalah melakukan perhitungan dengan menggunakan metode Signal Strength Based Linkstability Sensing (Ali, dkk., 2009). 


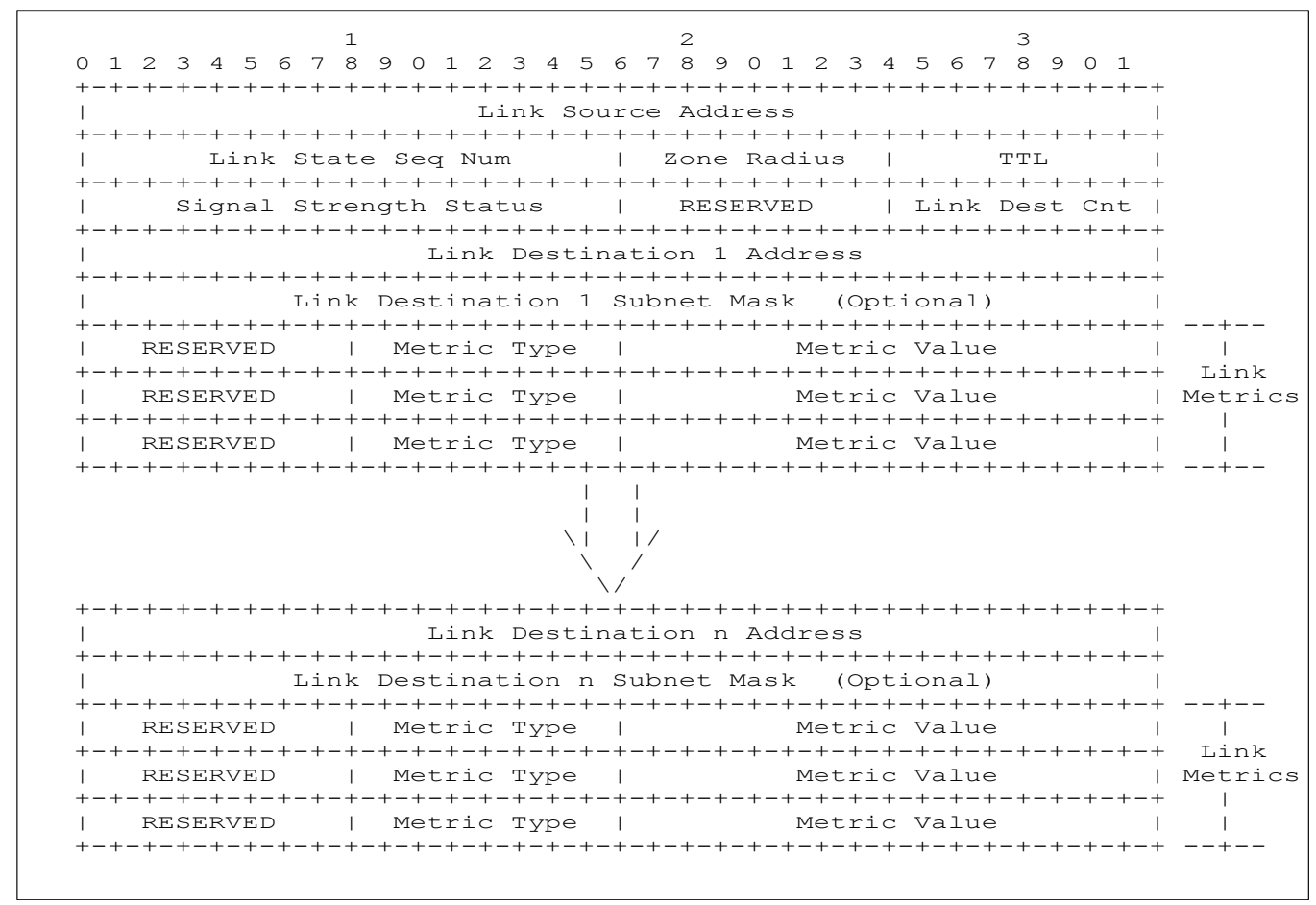

Gambar 12 Rancangan Paket Header LS-ZRP (J. Haas, dkk., 2003) 


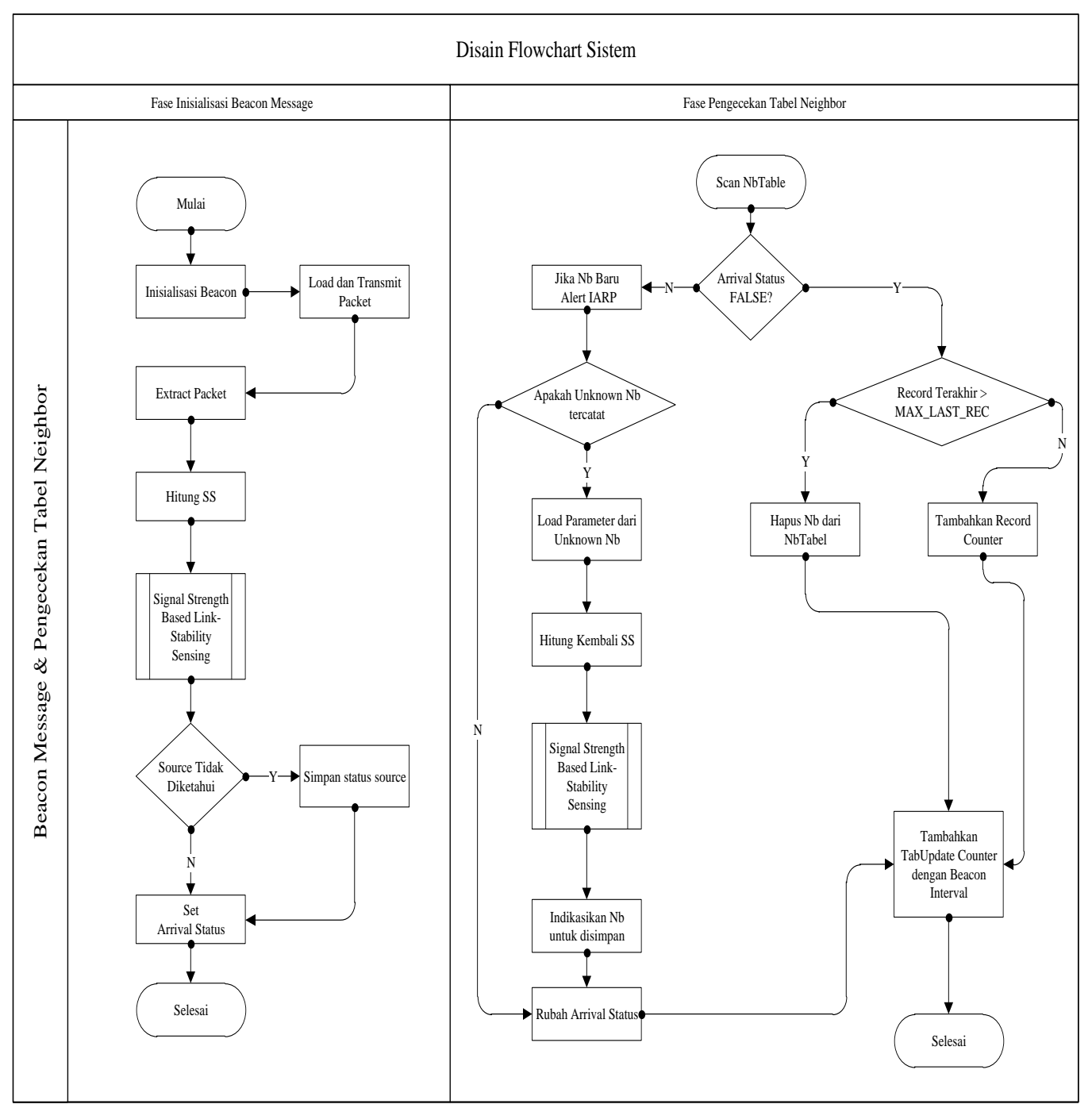

Gambar 13 Flowchart NDP dengan Link Stability Sensing

Untuk mengimplementasikan LS-ZRP pada simulator JiST/SWANS beberapa kode program perlu ditambahkan. Penambahan kode program dilakukan pada Class yang berkaitan dengan ZRP seperti RouteZrpNdp.java, RouteZrp.java, NetMessage.java. serta penambahan pada driver simulator yang befungsi sebagai scenario simulasi.

\section{PERANCANGAN SIMULASI SIS- TEM}

Sesuai dengan tujuan penelitian ini, yaitu untuk menghasilkan sebuah perbaikan mekanisme routing pada protokol ZRP dengan metode signal strength based link stability sensing, dinamai dengan LS-ZRP. Protokol tersebut diharapkan menghasilkan performa yang lebih tinggi dalam proses routing dibandingkan dengan protokol ZRP standar.

Perlu ditentukan parameter-parameter yang diamati untuk kedua protokol dalam melakukan pembandingan tersebut. Parameterparameter ini diamati dan dibandingkan nilainya antara routing protokol ZRP dan routing protokol LS-ZRP. Terdapat 3 (tiga) parameter yang diamati dalam penelitian ini end-to-end delay (e2e delay), throughput, dan routing overhead.

a. Parameter pertama adalah end-to-end delay atau e2e delay, merupakan waktu yang diperlukan mulai dari sebuah paket dikirimkan hingga paket tersebut diterima dan memberikan acknowledgement kepada pengirim paket. Semakin kecil nilai e2e delay, maka semakin bagus performa dari protokol tersebut. End-to-end delay dihitung dari file trace simulator JiST/SWANS dengan cara mencari selisih antara waktu paket tersebut dikirimkan dengan waktu paket tersebut diterima oleh node penerima. Perhitungan routing overhead dapat dilakukan dengan Persamaan 2.

$$
\text { e2edelay }=\frac{\sum \text { Waktu_Tempuh_Paket }}{\sum \text { Recieved_Packet }}
$$


b. Parameter kedua adalah throughput, merupakan total jumlah packet data yang diterima per detik oleh penerima. Throughput ini diperoleh dari dengan menhitung banyaknya paket yang diterima oleh penerima dibagi dengan waktu simulasi. Satuan yang digunakan adalah kilobit-per-second (kbps). Semakin besar nilai throughput semakin baik. Perhitungan throughput dapat dilakukan dengan Persamaan 3.

$$
\text { throughput }=\frac{\text { SPacket_size }}{(\text { stop_time-start_time })}
$$

c. Parameter ketiga adalah Routing Overhead, merupakan total jumlah paket yang di routing-kan berbanding dengan jumlah paket yang diterima oleh penerima. Routing overhead ini dapat diperoleh dengan cara menghitung banyaknya paket yang di-routing dibagi dengan banyaknya paket yang diterima oleh penerima. Hasil pembagian tersebut kemudian dikali $100 \%$ untuk mendapatkan hasil dari routing overhead dalam bentuk persen (\%). Perhitungan routing overhead dapat dilakukan dengan Persamaan 4.

Routing Overhead $=\frac{\sum \text { Routing }_{\text {Packet }}}{\sum \text { Packet }_{\text {Recieved }}}(\%)(4)$
Tabel 2 Keterangan simbol hasil packet trace

\begin{tabular}{|c|c|c|c|c|}
\hline $\begin{array}{l}\text { Trace } \\
\text { Tipe }\end{array}$ & Event & & $\begin{array}{l}\text { Tipe } \\
\text { Data }\end{array}$ & Keterangan \\
\hline \multirow{15}{*}{ Packet } & \multirow{15}{*}{$\begin{array}{l}\text { h: Hop } \\
\text { r: Re- } \\
\text { ceive } \\
\text { d: Drop } \\
\text { Line } \\
+: \\
\text { Enqueue } \\
\text {-: } \\
\text { Dequeue }\end{array}$} & $-t$ & time & Time \\
\hline & & $-S$ & int & Source ID \\
\hline & & $\overline{\mathrm{d}}$ & int & $\begin{array}{l}\text { Destination } \\
\text { ID }\end{array}$ \\
\hline & & $-e$ & int & Extent \\
\hline & & $-a$ & int & $\begin{array}{l}\text { Packet Color } \\
\text { Attribute ID }\end{array}$ \\
\hline & & $-\mathrm{i}$ & int & ID \\
\hline & & -1 & int & Energy \\
\hline & & $-\mathrm{c}$ & string & Conversation \\
\hline & & $\begin{array}{l}- \\
\mathrm{x}\end{array}$ & comment & Comment \\
\hline & & $\begin{array}{l}- \\
\mathrm{p}\end{array}$ & string & Packet Type \\
\hline & & $\begin{array}{l}- \\
\mathrm{k}\end{array}$ & string & Packet Type \\
\hline & & $\begin{array}{l}- \\
\mathrm{y}\end{array}$ & comment & \\
\hline & & $\begin{array}{l}- \\
\mathrm{S}\end{array}$ & int & \\
\hline & & $\begin{array}{l}- \\
\mathrm{m}\end{array}$ & int & \\
\hline & & $-f$ & int & \\
\hline
\end{tabular}

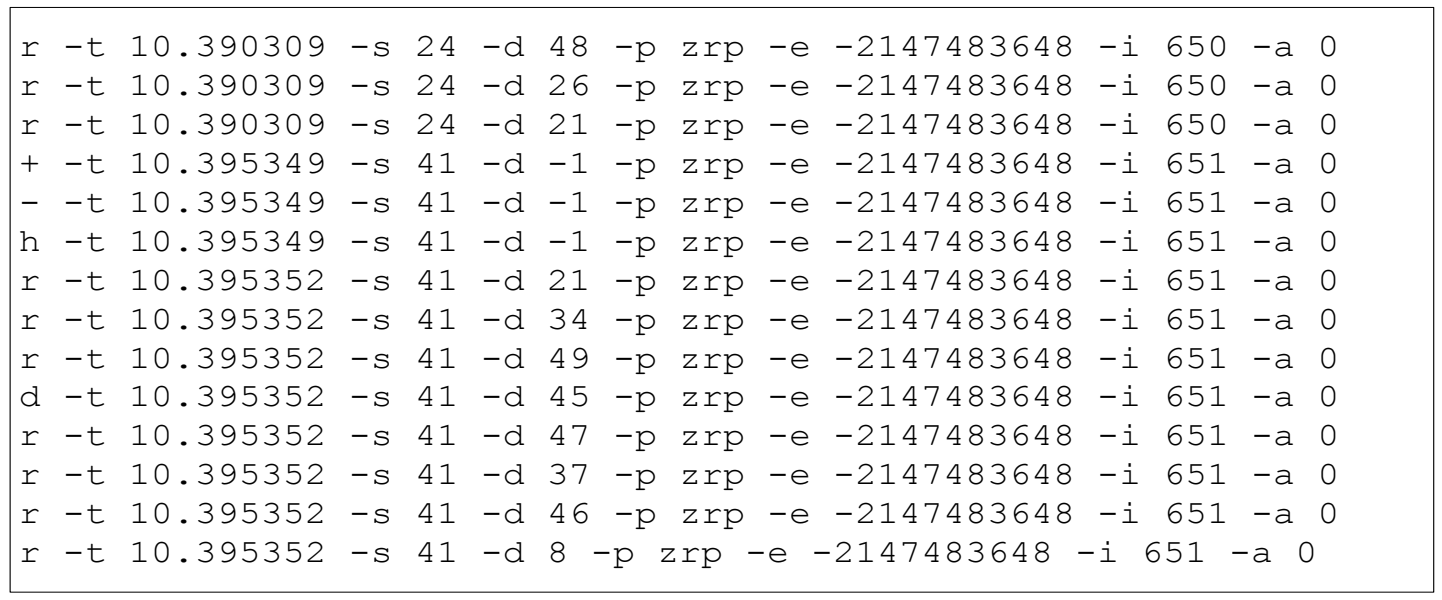

Gambar 14 Hasil Trace File

Hasil trace yang dihasilkan, kemudian akan diolah kembali untuk mendapatkan hasil sesuai dengan parameter-parameter yang diamati. Pengolahan dilakukan dengan menggunakan fungsi statistik yang dimiliki oleh JiST/SWANS dan kemudian dihitung dengan rumus dari masingmasing parameter yang diamati.

\subsection{Pembangunan Skrip untuk Pengujian}

Pada saat pembangunan skrip untuk pengujian, parameter-parameter simulasi ditentukan terlebih dahulu. Parameter-parameter simulasi tersebut adalah atribut-atribut tetap untuk setiap skenario pengujian, sehingga setiap skrip pengujian yang digunakan untuk simulator JiST/SWANS, dibangun berdasarkan parameter- 
parameter tersebut. Nilai-nilai untuk parameterparameter simulasi tersebut dijelaskan secara lebih terperinci dalam Tabel 2.

Tabel 3 Parameter-parameter Simulasi untuk Pengujian

\begin{tabular}{|c|c|c|}
\hline No & Parameter & Spesifikasi \\
\hline 1. & Simulator & JiST/SWANS \\
\hline 2. & Banyaknya Node & 50 \\
\hline 3. & Area Simulasi & $\begin{array}{lll}21000 \mathrm{~m} & \text { x } & 1000 \mathrm{~m}, \\
1500 \mathrm{~m} & \mathrm{x} & 1500 \mathrm{~m}, \\
2000 \mathrm{~m} & \mathrm{x} & 2000 \mathrm{~m}, \\
2500 \mathrm{~m} & \mathrm{x} & 2500 \mathrm{~m}, \\
3000 \mathrm{~m} \times & 3000 \mathrm{~m}\end{array}$ \\
\hline 4. & MAC protokol & IEEE 802.11b DCF \\
\hline 5. & Mode Propagasi & $\begin{array}{l}\text { Two-ray ground re- } \\
\text { flection model }\end{array}$ \\
\hline 6. & Mobility Model & Random Way Point \\
\hline 7. & Antennas Model & Omnidirectional \\
\hline 8. & Tipe Trafik & $\begin{array}{l}\text { Constant Bit Rate } \\
\text { (CBR) }\end{array}$ \\
\hline 9. & Kecepatan Node & $5 \mathrm{~m} / \mathrm{s}-50 \mathrm{~m} / \mathrm{s}$ \\
\hline 10. & Simulation Time & $\begin{array}{l}900 \text { s (waktu simu- } \\
\text { lasi) }\end{array}$ \\
\hline 11. & $\begin{array}{l}\text { Bordercast Transmis- } \\
\text { sion }\end{array}$ & $5,10,15,25,35,45$ \\
\hline 12. & Start Bordercast & $\begin{array}{l}\text { 100s (Setelah simu- } \\
\text { lasi berjalan sampai } \\
\text { akhir simulasi) }\end{array}$ \\
\hline 13. & Radio Radius & $250 \mathrm{~m}$ \\
\hline 14. & Source/Destination & Random \\
\hline
\end{tabular}

\begin{tabular}{|r|l|l|}
\hline & & Node \\
\hline 15. & ZRP Zone & 2 hope node \\
\hline 16. & Packet Drop & Uniform 0.02 \\
\hline 17. & Threshold_high & $\begin{array}{l}-8.9 \quad \text { (logarithmic } \\
\text { value) }\end{array}$ \\
\hline 18. & Delta & 0.2 \\
\hline 19. & Hyst_ss_scaling & 0.5 \\
\hline
\end{tabular}

Atribut-atribut pada Tabel 2 digunakan untuk membangun skrip pengujian pada skenario pengujian. Adapun skrip skenario pengujian sistem dijelaskan pada sub-bab berikut.

\subsection{Skrip Pengujian}

Skrip pengujian ini merupakan hasil dari penentuan nilai yang dilakukan. Penentuan nilai pengujian kemudian diimplementasikan ke simulator dalam bentuk skrip pengujian. Pada Gambar 5 diperlihakan skrip yang berisikan nilai yang digunakan untuk pengujian. Pada skenario pengujian sistem yang dilakukan, adalah memvariasikan luas wilayah yaitu $1000 \times 1000 \mathrm{~s} / \mathrm{d}$ 3000x3000. Nilai tersebutlah yang dimasukan kedalam skrip pada Gambar 2, nilai yang dirubah adalah nilai yang ditandai dengan warna hijau yaitu luas wilayah dari simulasi yang dilakukan. Sedangkan nilai yang lain di setting sama dengan luas wilayah yang lain.

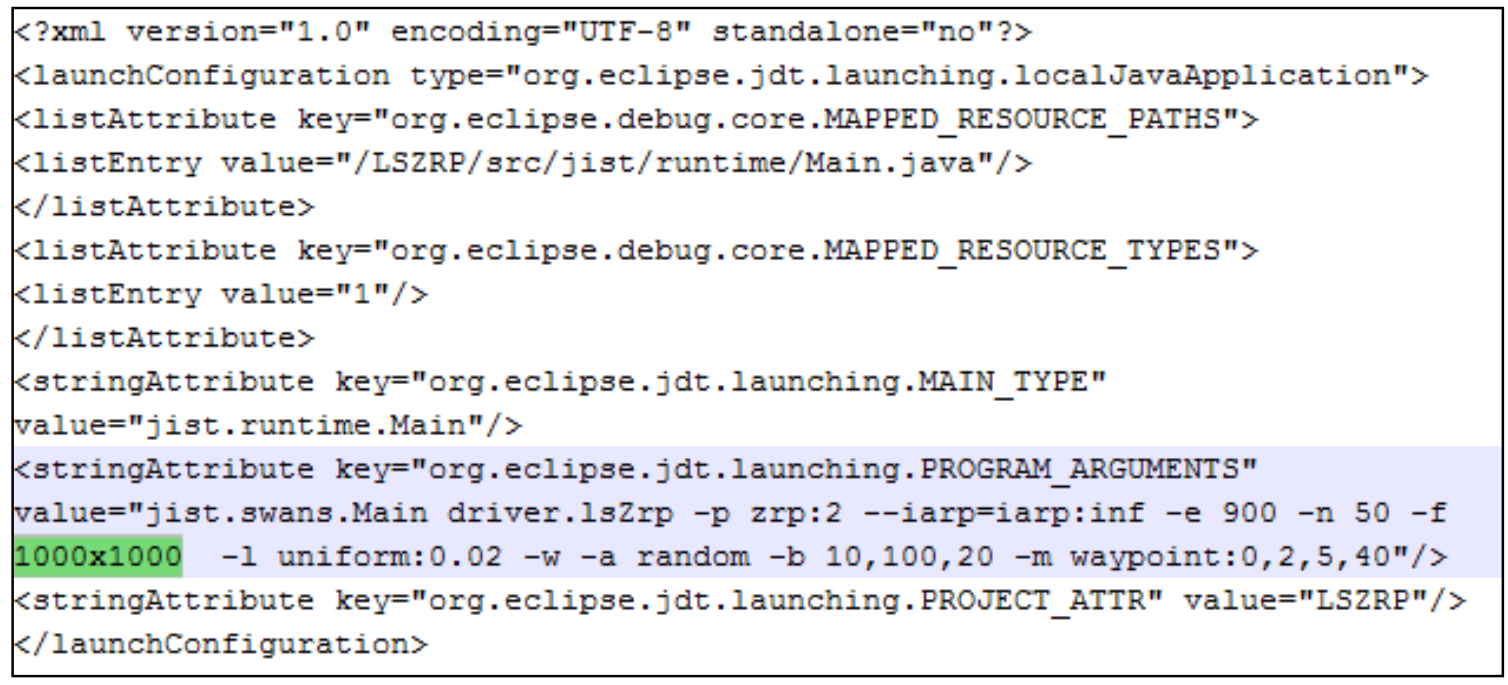

Gambar 15 Contoh skrip pengujian

Skenario sistem berdasarkan skrip pada Gambar 2 akan dijalankan pada simulator JiST/SWANS. Skrip pengujian sistem tersebut akan menghasilkan file trace yang kemudian dioalah kembali untuk mendapakan hasil sesuai dengan parameter yang diamati yaitu $e 2 e$ delay, throughput, dan routing overhead.

\section{HASIL DAN PEMBAHASAN}

Pada bagian ini akan dilakukan evaluasi kinerja dari metode pemilihan node tetangga yang di-ajukan dengan melihat hasil parameter yang diamati dan perbandingan dengan protokol ZRP standar. Metode yang diajukan diimplementasikan 
dengan bahasa pemrograman Java dan disimulasikan menggunakan simulator JiST/SWANS, pada sebuah komputer dengan spesifikasi Processor Intel Core i3-2120 3,3 Ghz, 4 Core, RAM 4 GB, (2,92 GB useable), Hardisk 500 GB, Sistem Operasi Windows 7 32-bit.

\subsection{Parameter Uji Coba}

Adapun parameter pengujian simulator yang digunakan untuk menguji sistem yang dibuat adalah seperti terlihat pada tabel 3.1

Tabel 4 Parameter Pengujian pada Simulator

\begin{tabular}{|c|c|c|}
\hline No & Parameter & Spesifikasi \\
\hline 1. & Simulator & JiST/SWANS \\
\hline 2. & Banyaknya Node & 50 \\
\hline 3. & Area Simulasi & $\begin{array}{lll}21000 \mathrm{~m} & x & 1000 \mathrm{~m}, \\
1500 \mathrm{~m} & x & 1500 \mathrm{~m}, \\
2000 \mathrm{~m} & x & 2000 \mathrm{~m}, \\
2500 \mathrm{~m} & x & 2500 \mathrm{~m}, \\
3000 \mathrm{~m} \times & 3000 \mathrm{~m}\end{array}$ \\
\hline 4. & MAC protokol & IEEE 802.11b DCF \\
\hline 5. & Mode Propagasi & $\begin{array}{l}\text { Two-ray ground re- } \\
\text { flection model }\end{array}$ \\
\hline 6. & Mobility model & Random Way Point \\
\hline 7. & Antennas Model & Omnidirectional \\
\hline 8. & Traffic type & $\begin{array}{l}\text { Constant Bit Rate } \\
\text { (CBR) }\end{array}$ \\
\hline 9. & Speed of node & $5 \mathrm{~m} / \mathrm{s}-50 \mathrm{~m} / \mathrm{s}$ \\
\hline 10. & Simulation Time & $900 \mathrm{~s}$ \\
\hline 11. & $\begin{array}{l}\text { Bordercast Transmis- } \\
\text { sion }\end{array}$ & $5,10,15,25,35,45$ \\
\hline 12. & Start Bordercast & $\begin{array}{l}\text { 100s (Setelah simu- } \\
\text { lasi berjalan sampai } \\
\text { akhir simulasi) }\end{array}$ \\
\hline 13. & Radio Radius & $250 \mathrm{~m}$ \\
\hline 14. & Source/Destination & Random dalam Node \\
\hline 15. & Waktu Simulasi & $\begin{array}{l}900 \text { detik (waktu } \\
\text { simulator) }\end{array}$ \\
\hline
\end{tabular}

\subsection{Skenario Uji Coba}

Skenario pengujian pada penelitian ini dibagi menjadi 3 sesuai dengan pembahasan pada bab 3. Skenario pengujian ini dilakukan untuk membuktikan kebenaran dan mengetahui kinerja protokol routing ZRP yang telah dimodifikasi dengan menambahkan metode signal strength based link-stabiliy sensing yang kemudian menjadi LS-ZRP (Link-Stability Zone Routing Protocol).

Pada skenario ini wilayah simulasi dirancang sedemikian rupa dengan bentuk persegi dan luas wilayahnya divariasikan yaitu 1000x1000, 1500x1500, 2000x2000, 2500x2500 dan $3000 x 3000$, luas wilayah ini dalam satuan meter. Jumlah node yang disimulasikan adalah 50 node dengan jumlah transmisi bordercast sebanyak 10 , start bordercast 100 s setelah simulasi berjalan (waktu simulasi) delay bordercast 10, waktu simulasi mengacu pada tabel 3.1 parameter uji yaitu serta untuk kecepatan node divariasikan mulai $5 \mathrm{~m} / \mathrm{s}$ $-40 \mathrm{~m} / \mathrm{s}$.

Pada JiST/SWANS skenario diatas diimplentasikan pada antarmuka driver. Protokol lapisan MAC yang digunakan adalah IEEE 802.11b Distributed Coordination Function (DCF). DCF didesain dengan menggunakan mekanisme CSMA/CA dan algoritma binary exponential backoff untuk mengurangi kemungkinan terjadinya collision. Selain itu, DCF juga menerapkan skema positive acknowledge, yang mana jika sebuah frame telah diterima dengan benar oleh node tujuan, node tujuan harus mengirimkan frame ACK kepada node sumber.

Model propagasi radio yang digunakan adalah model Two Ray Ground. Model ini mempertimbangkan dua aspek, yaitu lintasan lurus antara transmitter node dengan receiver node dan pantulan permukaan bumi. Lintasan antara transmitter node dengan receiver node diasumsikan memenuhi kondisi line of sight, yang artinya tidak ada penghalang di antara node tujuan dengan node sumber. Sehingga sesuai untuk simulasi yang memerlukan jangkauan transmitter yang jauh. Pada penelitian ini jangkauan transmisi adalah 250 meter, tinggi 43tatist adalah 1.5 meter yang ditempatkan sedemikian rupa tepat di tengah mobile node.

Untuk melakukan uji stressing terhadap kemampuan routing protocol ketika melakukan prosedur route discovery dan route maintenance tanpa menimbulkan kongesti yang berlebihan, Constant Bit Rate (CBR) dipilih sebagai model komunikasi antar node yang uniform. CBR merupakan aplikasi yang berjalan di atas transport UDP. Node sumber akan mengirim trafik CBR dalam paketpaket data sebesar 512 bytes dengan kecepatan 4 paket per detik. Selama simulasi berlangsung.

Model mobilitas menggambarkan bagaimana node bergerak pada area simulasi. Model mobilitas yang digunakan pada penelitian ini adalah random waypoint. Model mobilitas random waypoint dipilih karena mayoritas simulasi menggunakan model ini dan merupakan model pergerakan standar pada JiST/SWANS. Pada model random waypoint, posisi awal setiap mobile node dipilih secara acak pada area simulasi. Kecepatan mobile node dipilih secara acak di antara kecepatan minimal dan kecepatan minimal. Kecepatan minimal diberi nilai $1 \mathrm{~m} / \mathrm{s}$ agar kecepatan mobile node dapat mencapai kondisi yang stabil dan konvergen dengan cepat.

Setelah pembuatan program skenario selesai, maka langkah selanjutnya adalah menjalankan simulasi program tersebut. Simulasi program menghasilkan trace file dengan ekstensi tr. Trace file ini berisi informasi-informasi yang diperlukan untuk analisa kinerja routing protocol. 
Dalam simulator JiST/SWANS, pembuatan trace file untuk mendapatkan hasil berupa animasi jaringan atau disebut dengan NAM, membutuhkan library tambahan yaitu library guiTrace. guiTrace akan menghasilkan file berekstensi .nam. NAM merupakan singkatan dari Network Animator, sehingga simulasi driver dengan tambahan library guiTrace dapat dianimasikan dengan program aplikasi NAM.

\subsection{Hasil Uji Coba}

Hasil uji coba dari skenario yang telah dilakukan akan ditampilkan dalam bentuk tabel yang berisikan data dari parameter-parameter yang diamati, yaitu routing overhead, throughput, dan $e 2 e$ delay

Tabel 5 Hasil Uji Coba

\begin{tabular}{ccccccc}
\hline \multirow{2}{*}{ Luas Area } & \multicolumn{2}{c}{ Routing Overhead } & \multicolumn{2}{c}{ Throughput } & \multicolumn{2}{c}{ e2e delay } \\
\cline { 2 - 7 } & LS-ZRP & ZRP & LS-ZRP $(\mathrm{kbps})$ & ZRP $(\mathrm{kbps})$ & LS-ZRP $(\mathrm{ms})$ & ZRP $(\mathrm{ms})$ \\
\hline $1000 \times 1000$ & $63.99 \%$ & $50.82 \%$ & 35.56 & 44.77 & 204.76 & 162.63 \\
$1500 \times 1500$ & $\mathbf{2 3 . 6 9 \%}$ & $\mathbf{2 4 . 1 9 \%}$ & $\mathbf{9 6 . 0 6}$ & $\mathbf{9 4 . 0 6}$ & $\mathbf{7 5 . 8 0}$ & $\mathbf{7 7 . 4 1}$ \\
$2000 \times 2000$ & $29.30 \%$ & $34.83 \%$ & 77.66 & 65.34 & 93.76 & 111.45 \\
$2500 \times 2500$ & $45.62 \%$ & $55.19 \%$ & 49.86 & 41.10 & 146.04 & 164.00 \\
$3000 \times 3000$ & $66.64 \%$ & $83.33 \%$ & 33.51 & 26.76 & 217.33 & 272.11 \\
\hline
\end{tabular}

\subsection{Hasil Uji Coba Parameter Routing Overhead}

Routing Overhead adalah total jumlah paket yang di routing-kan berbanding dengan jumlah paket yang diterima oleh penerima. Untuk mendapatkan nilai presentase maka hasil Routing Overhead dikalikan $100 \%$.

Untuk mendapatkan nilai dari routing overhead setiap skenario, digunakanlah rumus sebagai berikut:

Routing Overhead

$$
=\frac{\sum \text { Routing_Packet }}{\sum \text { Packet_Recieved }}(\%)
$$

$$
\begin{aligned}
\text { Routing Overhead } & =\frac{50896}{89899}(\%) \\
\text { Routing Overhead } & =0.5661 \times 100 \% \\
\text { Routing Overhead } & =56.61 \%
\end{aligned}
$$

Hasil yang didapatkan dari rumus diatas selanjutnya akan disimpan ke dalam bentuk tabel yang kemudian diolah menjadi garfik yang bisa dianalisa.

Data Routing Overhead pada Tabel 5 adalah data hasil pengujian skenario yang telah dilakukan dengan variasi luas area yang disimulasikan. Terdapat 5 variasi luas area yang terdapat pada 5. Dari data hasil pengujian skenario yang telah dilakukan pada Tabel 5 terlihat Routing Overhead LS-ZRP lebih tinggi dibandingkan dengan ZRP pada luas wilayah 1000x1000 meter. Nilai Routing Overhead LS-ZRP sebesar 63.99\% sedangkan nilai Routing Overhead ZRP sebesar $50.82 \%$ pada luas area $1000 \times 1000$ meter. Untuk luas area 1500x1500 meter Routing Overhead dari LS-ZRP mengalami penurunan yang sangat signifikan yaitu dari $63.99 \%$ menjadi $23.69 \%$. Penurunan
Routing Overhead juga terlihat pada ZRP yaitu dari $50.82 \%$ menjadi $24.19 \%$.

Routing Overhead mengalami peningkatan setelah luas area menjadi 2000x2000 meter. LSZRP dan ZRP sama-sama mengalami peingkatan Routing Overhead, pada luas area 2000x2000 meter, namun peningkatan nilai Routing Overhead dari LS-ZRP lebih rendah dibandingkan dengan nilai Routing Overhead ZRP. Peningkatan nilai Routing Overhead LS-ZRP dari $23.96 \%$ menjadi $29.30 \%$ sedangkan nilai Routing Overhead ZRP dari $24.19 \%$ menjadi $34.83 \%$. Trend nilai Routing Overhead dari protokol LS-ZRP dan ZRP mengalami peningkatan seiring dengan menigkatnya luas area. Secara keseluruhan nilai Routing Overhead LS-ZRP masih lebih baik dengan rata-rata nilai Routing Overhead sebesar $45.85 \%$ sedangkan rata-rata nilai Routing Overhead dari ZRP adalah 49.67\%. Selisih rata-rata nilai Routing Overhead dari LS-ZRP dan ZRP adalah $3.83 \%$.

Grafik dari Gambar 6 memiliki trend yang sama dengan grafik $e 2 e$ delay pada Gambar 8. grafik $e 2 e$ delay trend-nya adalah mengalami penurunan pada saat luas wilayah 1500x1500 meter dan grafik Routing Overhead pada Gambar 6 juga mengalami penurunan pada area yang sama. Grafik Routing Overhead kembali mengalami penigkatan seiring dengan naiknya nilai e2e delay yang diikuti oleh bertambahnya luas area. Jadi ketika nilai $e 2 e$ delay mengalami penurunan maka nilai Routing Overhead juga akan mengalami penurunan, hal ini disebabkan oleh semakin tingginya Routing Overhead maka nilai e2e delay juga akan meningkat. Karena pada proses Routing, paket akan mengalami pengecekan node, jadi semakin lama pengecekan 
yang terjadi maka nilai $e 2 e$ delay juga akan bertambah semakin lama.

\subsection{Hasil Uji Coba Parameter Throughput}

Throughput merupakan jumlah paket yang diterima dalam setiap detiknya. Hasil perihitungan Throughput yang didapatkan dari skenario yang telah dilakukan dimuat dalam satu tabel antara Throughput LS-ZRP dan ZRP.

Peritungan Throughput bisa dilakukan dengan menggunakan rumus sebagai berikut:

$$
\begin{aligned}
& \text { throughput } \\
& =\frac{\sum \text { packet_size }}{\text { stop }_{\text {time }}-\text { Start }_{\text {time }}} \mathrm{kbps} \\
& \text { throughput }=\frac{29448}{800} \mathrm{kbps} \\
& \text { throughput }=36.81 \mathrm{kbps}
\end{aligned}
$$

Dari perhitungan dengan menggunakan rumus diatas maka didapatlah data yang selanjutnya dijadinkan sebuah tabel yang terlihat seperti Tabel 5. Tabel hasil throughput selanjutkan akan dianalisis dan disajikan dalam bentuk grafik.

Data yang diperlihatkan pada Tabel 5 adalah data hasil pengujian yang telah dilakukandengan variasi luas area yang disimulasikan. Terdapat 5 variasi luas area yang terdapat pada Tabel 5. Dari data hasil pengujian yang telah dilakukan pada Tabel 5 terlihat Throughput LS-ZRP lebih kecil dibandingkan dengan ZRP pada luas wilayah 1000x1000 meter. Nilai Throughput LSZRP sebesar 35.56 kbps sedangkan nilai Through- put ZRP sebesar $44.77 \mathrm{kbps}$ pada luas area 1000x1000 meter. Untuk luas area 1500x1500 meter Throughput dari LS-ZRP mengalami penigkatan yang sangat signifikan yaitu dari $35.56 \mathrm{kbps}$ menjadi 96.06 kbps. Peningkatan Throughput juga terlihat pada ZRP yaitu dari $44.77 \mathrm{kbps}$ menjadi 94.06 kbps.

Nilai Throughput mengalami penurunan setelah luas area menjadi 2000x2000 meter. LSZRP dan ZRP sama-sama mengalami penurunan Throughput, pada luas area $2000 \times 2000$ meter, namun penurunan nilai Throughput dari LS-ZRP lebih rendah dibandingkan dengan nilai Throughput ZRP. Penurunan nilai Throughput LS-ZRP dari 96.06 kbps menjadi 77.66 kbps sedangkan nilai Throughput ZRP dari $94.06 \mathrm{kbps}$ menjadi 65.43 kbps. Trend nilai Throughput dari protokol LSZRP dan ZRP mengalami penurunan seiring dengan menigkatnya luas area. Secara keseluruhan nilai Throughput LS-ZRP masih lebih baik dengan rata-rata nilai Throughput sebesar 58,53 kbps sedangkan rata-rata nilai Throughput dari ZRP adalah 54,41 kbps. Selisih rata-rata nilai Throughput dari LS-ZRP dan ZRP adalah $4.13 \mathrm{kbps}$.

Grafik dari Gambar 7 memiliki trend yang sama dengan grafik e 2 e delay pada Gambar 8 tetapi dengan nilai yang terbalik. Pada grafik e2e delay trend-nya adalah mengalami penurunan pada saat luas wilayah 1500x1500 meter sedangan untuk grafik Throughput pada Gambar 4.17 mengalami peningkatan pada area yang sama.

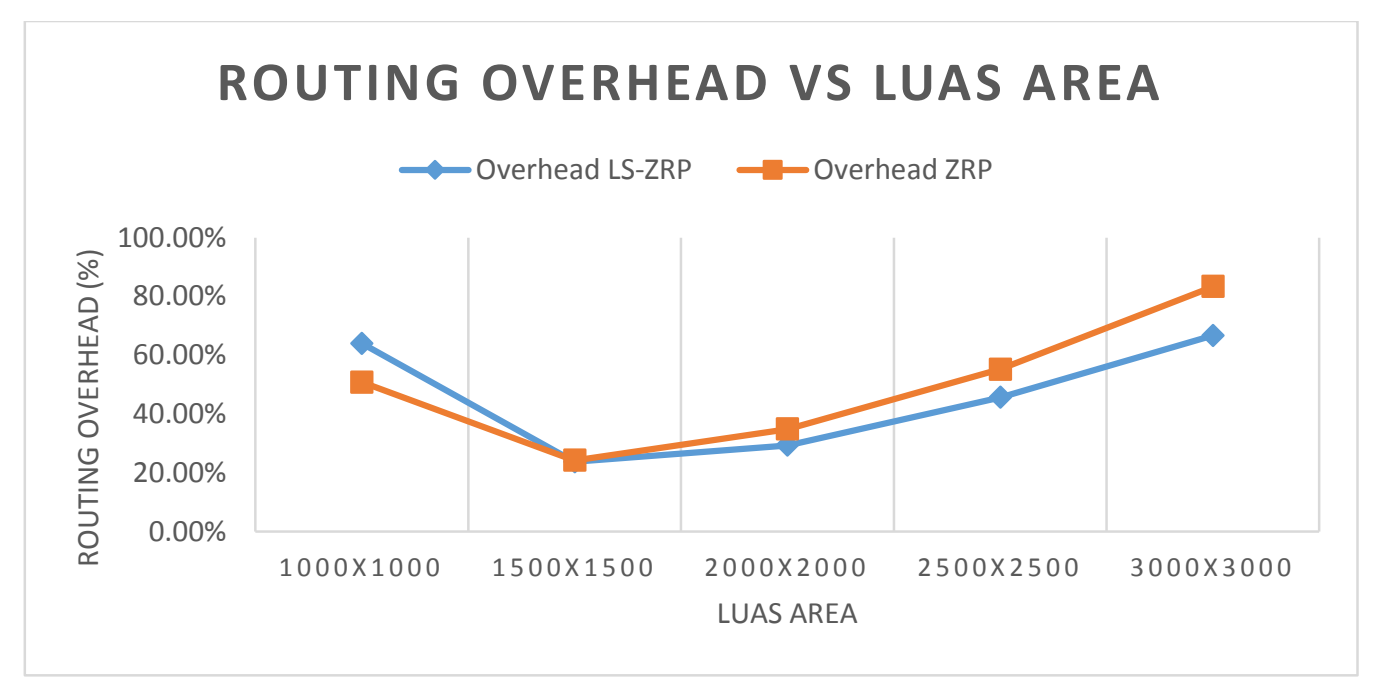

Gambar 16 Grafik Routing Overhead vs Luas Area 


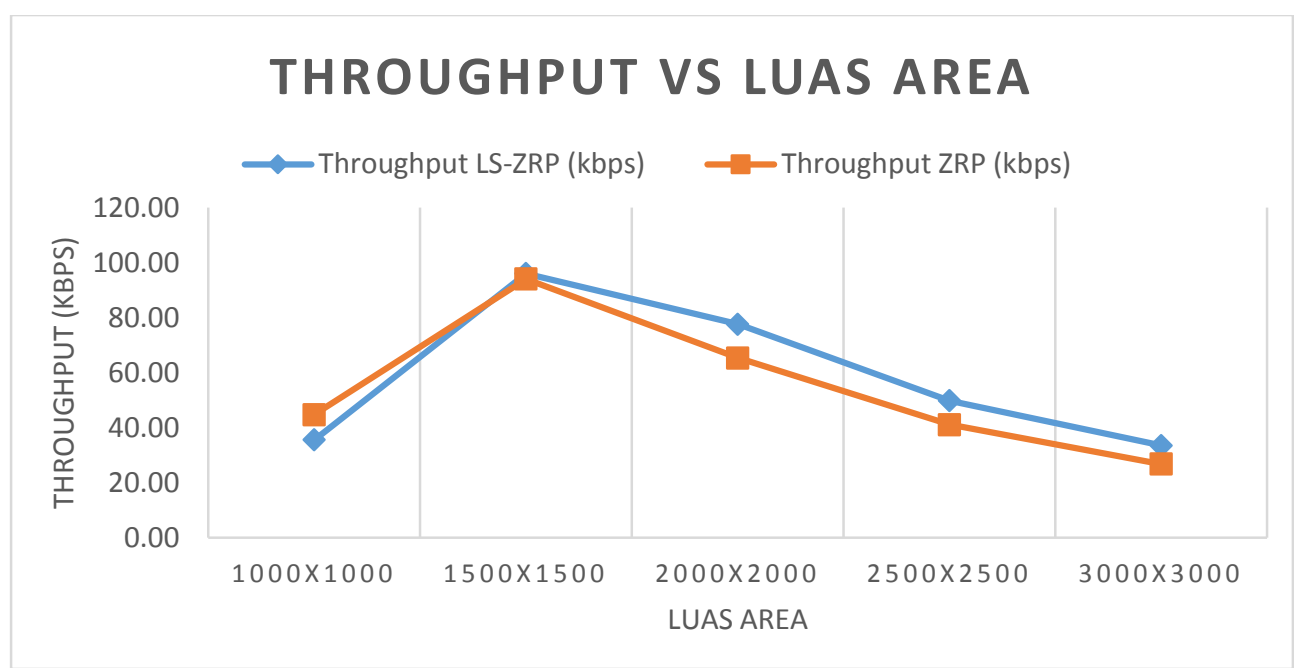

Gambar 17 Grafik Throughput vs Luas Area

Grafik Throughput kembali mengalami penurunan seiring dengan naiknya nilai $e 2 e$ delay yang diikuti oleh bertambahnya luas area. Jadi ketika nilai $e 2 e$ delay mengalami penurunan maka nila Throughput akan mengalami peningkatan, hal ini disebabkan oleh semakin tingginya $e 2 e$ delay maka jumlah data yang diterima akan semakin sedikit, begitu juga sebaliknya semakin sedikit ren-

\subsection{Hasil Uji Coba Parameter e2e delay}

End-to-end delay (e2e delay) merupakan perbandingan antara jumlah waktu transmisi packet dari source ke destination dengan jumlah packet yang diterima. Peritungan $e 2 e$ delay bisa dilakukan dengan menggunakan rumus sebagai berikut:

$$
\begin{aligned}
& \text { e2edelay }=\frac{\sum \text { Waktu_Tempuh_Paket }}{\sum \text { Recieved_Packet }} \\
& \text { e2edelay }=\frac{325399 \mathrm{~ms}}{5880} \\
& \text { e2edelay }=55.3399 \mathrm{~ms}
\end{aligned}
$$

Dari hasil perhitungan di atas maka nilai dari e2e delay $55.3399 \mathrm{~ms}$, yang didapatkan dari keseluruhan waktu tempuh packet, yakni 325.399 ms dibagi dengan banyaknya packet yang diterima yakni 5880 packet.

Hasil e2e delay dari keseluruhan skenario disajikan ke dalam bentuk yaitu Tabel 5. Tabel tersebut dibagi menjadi 3 bagian skenario dan masing-masing skenario dibagi menjadi 2 bagian yaitu LS-ZRP dan ZRP.

Pada Tabel 5 terlihat $e 2 e$ delay LS-ZRP lebih besar dibandingkan dengan ZRP pada luas wilayah 1000x1000 meter. Nilai e2e delay LS-ZRP sebesar $204.76 \mathrm{~ms}$ sedangkan nilai $e 2 e$ delay ZRP sebesar $162.63 \mathrm{~ms}$ pada luas area $1000 \times 1000$ meter. Untuk luas area $1500 \times 1500$ meter $e 2 e$ delay dari LS-ZRP mengalami penurunan yang sangat signifikan yaitu dari $204.76 \mathrm{~ms}$ menjadi $75.80 \mathrm{~ms}$. Penurunan $e 2 e$ delay juga terlihat pada ZRP yaitu dari $162.63 \mathrm{~ms}$ menjadi $77.41 \mathrm{~ms}$.

Trend peningkatan nilai e2e delay terjadi setelah luas area menjadi 2000x2000 meter. LS- dah nilai e2e delay maka jumalh data yang bisa dilewatkan akan semakin besar juga.

keseluruhan Throughput LS-ZRP masih lebih baik dari ZRP terbukti dari nilai rata-rata throughput LS-ZRP yaitu sebesar $80.31 \mathrm{kbps}$, serta untuk nilai rata-rata throughput ZRP adalah sebesar $67.29 \mathrm{kbps}$, dengan selisih rata-rata antara LS-ZRP dengan ZRP yaitu sebesar $13.02 \mathrm{kbps}$.

ZRP dan ZRP sama-sama mengalami peningkatan $e 2 e$ delay, pada luas area $2000 \times 2000$ meter, namun peningkatan nilai $e 2 e$ delay dari LS-ZRP lebih rendah dibandingkan dengan nilai $e 2 e$ delay ZRP. Peningkatan nilai e2e delay LS-ZRP dari $75.80 \mathrm{~ms}$ menjadi $93.76 \mathrm{~ms}$ sedangkan nilai e2e delay ZRP dari $77.41 \mathrm{~ms}$ menjadi $111.45 \mathrm{~ms}$. Trend nilai $e 2 e$ delay dari protokol LS-ZRP dan ZRP mengalami peningkatan seiring dengan menigkatnya luas area. Secara keseluruhan nilai $e 2 e$ delay LS-ZRP masih lebih baik dengan rata-rata nilai $e 2 e$ delay sebesar $147.54 \mathrm{~ms}$ sedangkan rata-rata nilai $e 2 e$ delay dari ZRP adalah $157,52 \mathrm{~ms}$. Selisih rata-rata nilai $e 2 e$ delay dari LS-ZRP dan ZRP adalah $9.98 \mathrm{~ms}$.

Representasi dari analisis yang dilakukan terhadap data $e 2 e$ delay hasil pengujian yang telah dilakukandapat dilihat pada Gambar 8. Grafik $e 2 e$ delay dari pengujian yang telah dilakukanmengalami penurunan pada saat luas area berubah dari 1000x1000 meter menjadi 1500x1500 meter. Tingginya delay pada luas area 1000x1000 meter disebabkan oleh kepadatan node (density), dimana pada saat itu jumlah node yang disimulasikan berjumlah 50 dengan luas wilayah 1000x1000 meter. Area ini dikategorikan sempit untuk jumlah node 50 , seperti yang terlihat pada Gambar 8 nilai $e 2 e$ delay dari LS-ZRP lebih tinggi dibandingkan dengan nilai $e 2 e$ delay dari ZRP pada area $1000 \times 1000$ meter. 


\section{AVERAGE E2E DELAY VS LUAS AREA}

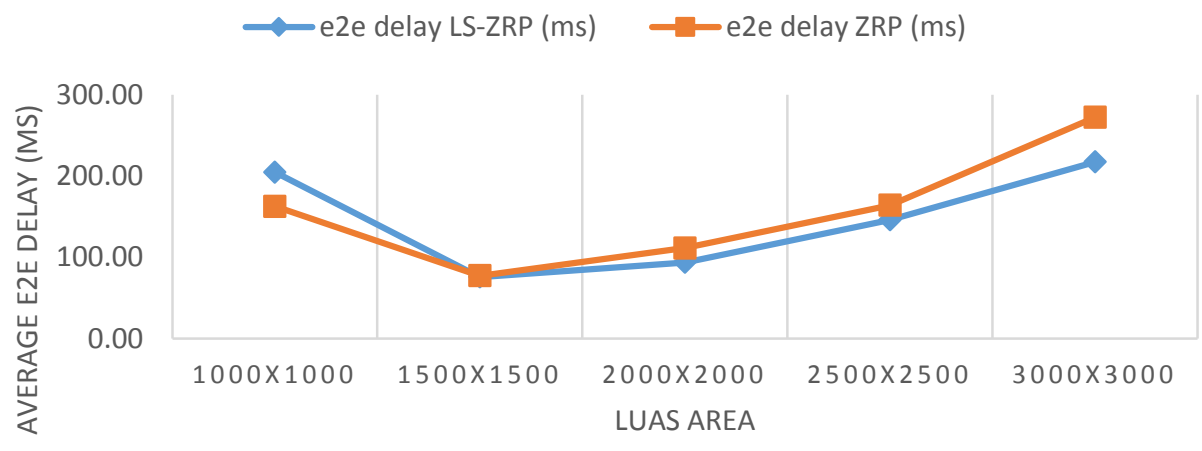

Gambar 18 Grafik Average e2e delay vs Luas Area

LS-ZRP memiliki nilai e2e delay lebih tinggi dikarenakan oleh adanya perhitungan signal strength dan link-stability yang diadaptasi pada protokol tersebut, jadi dengan adanya penambahan perhitungan kalkulasi signal strength dan linkstability pada area yang memiliki kepadatan node, menyebabkan LS-ZRP mendapatkan nilai $e 2 e$ delay lebih tinggi dibandingkan dengan ZRP yang tidak menggunakan perhitungan tersebut

Dapat dilihat juga pada grafik Gambar 8 nilai e2e delay antara LS-ZRP dengan ZRP samasama mengalami penurunan pada luas wilayah $1500 \times 1500$ meter, penurunan nilai $e 2 e$ delay dari kedua protokol sangat signifikan, hal ini disebabkan karena pada luas wilayah 1500x1500 meter dengan jumlah node 50 dan kecepatan node bervariasi dari $5 \mathrm{~m} / \mathrm{s}-40 \mathrm{~m} / \mathrm{s}$ serta Bordercast Transmission 10 dengan zone hop adalah 2 node, merupakan setingan yang paling optimun. Jadi perbandingan antara jumlah node, kecepatan node, bordercast transmision dan zona hop, merupakan settingan yang paling tepat untuk digunakan pada saat area berukuran 1500x1500 meter. Grafik pada Gambar 8 memperlihatkan trend meningkat setelah luas wilayah berubah menjadi lebih besar. Kedua protokol menunjukan trend yang sama akan tetapi untuk LS-ZRP pada trend naik ini masih lebih bagus dari pada ZRP.

\section{KESIMPULAN}

Berdasarkan hasil uji coba yang telah dilakukan, metode yang diterapkan pada protokol ZRP, mampu menghasilkan nilai lebih baik dibandingkan dengan protokol ZRP standar. Hal ini dibuktikan dengan peningkatan nilai throughput sebesar $4.13 \mathrm{kbps}$, penurunan e2e delay sebesar $9.98 \mathrm{~ms}$, dan penurunan routing overhead sebesar $3.83 \%$.

\section{DAFTAR PUSTAKA}

Ali, H. M. i., Naimi, A. M., Busso, A. \& Veque, V., (2009). Signal Strength Based Link Sensing for Mobile Ad-Hoc Networks. Telecommunication Systems, Desember, 42(3-4), hal. 201-212.

Asha, A., Sharma, H. \& Mohabey, V. K., (2012). Improved AODV Protocol For Solving Link Failure in MANET. International Journal of Scientific \& Engineering Research, Oktober, 3(10), hal. 1-6.

Beijar, N., (2002). Zone Routing Protocol (ZRP). [Online]

Tersedia di:

http://www.netlab.hut.fi/opetus/s38030/k02/ Papers/08-Nicklas.pdf

[Accessed 4 Jaruari 2013].

C. Biradar, R. \& S. Manvi, S., (2012). Neighbor supported reliable multipath multicast routing in MANETs. Journal of Network and Computer Applications, Volume 35, hal. 1074-1085.

J. Haas, Z., Pearlman, M. R. \& Samar, P., (2003). The Zone Routing Protocol (ZRP) for Ad Hoc Networks. [Online] Tersedia di: http://tools.ietf.org/html/draftietf-manet-zone-zrp-04

[Accessed 3 Januari 2013].

Jain, S., Kokate, S., Thakur, P. \& Takalkar, S., (2012). A Study of Congestion Aware Adaptive Routing Protocols in MANET. Computer Engineering and Intelligent Systems, 3(4), hal. 64-73.

Ravilla, D. \& Putta C., S. R., (2012). Energy Management in Zone Routing Protocol 
48 Jurnal Ilmu Komputer Vol.VI, No. 2, September 2013, hlm.35-48

(ZRP). International Journal of Emerging Technology and Advanced Engineering, Mei, 2(5), hal. 61-68.

Shafiq, Z. et al., (2012). Zone Routing Protocol: How does it Perform the How does it Perform the. Peshawar, s.n., hal. 71-77.

Wrona, K. \& Mahonen, P., (2004). Analytical model of cooperation in ad hoc Networks. Telecommunication Systems, Volume 27, hal. 347-369. 